\title{
HUBUNGAN PENERAPAN SISTEM MANAJEMEN K3 DENGAN MOTIVASI KERJA DAN STRES KERJA PADA PERAWAT DI RUMAH SAKIT
}

\author{
Muhaini Atmayana Purba / 181101131 \\ muhainipurba21@gmail.com
}

\begin{abstract}
ABSTRAK
Latar belakang : Kementerian kesehatan menyatakan akreditasi adalah langkah untuk menjamin rumah sakit agar mengutamakan pelayanan, keselamatan dan perlindungan masyarakat, sehingga akreditasi wajib bagi pelayanan kesehatan. Tujuan : Tujuan penulisan ini yaitu mengidenifikasi hubungan penerapan sistem manajemen $\mathrm{k} 3$ dengan motivasi kerja dan stres kerja pada perawat di rumah sakit. Metode : Metode yang digunakan merupakan literatur review atau suatu perbandingan atau analisis antara satu jurnal dengan jurnal lainnya dari berbagai sumber seperti referensi jurnal, buku teks dan e-book. Hasil : Hasil dari analisis ini menyatakan Responden akreditasi penting dilaksanakan. Dampak positif akreditasi adalah peningkatan kepedulian perawat pada indikator keselamatan pasien, yaitu pebaikan pada alur pelaporan masalah, kepatuhan terhadap standar operasional prosedur, komunikasi antar pertugas kesehatan, pendokumentasian, fasilitas pelayanan, pendidikan kesehatan, lingkungan kerja dan adanya pendidikan berkelanjutan. Kesimpulan : pandangan positif terhadap kegiatan akreditasi menjadi awal yang baik bagi rumah sakit untuk melanjutkan langkah perbaikan kualitas pelayanan. Karena hal utama dalam pelayanan adalah kualitas pelayanan yang dinilai dari indikator klinis pelayanan, bukan kelengkapan dokumentasi.
\end{abstract}

Kata Kunci : Penerapan, manajemen k3. Motivasi kerja, stres kerja, rumah sakit

\begin{abstract}
Background : The Ministry of Health states that accreditation is a step to guarantee hospitals to prioritize services, safety and community protection, so that accreditation is mandatory for health services. Purpose : The purpose of this paper is to identify the relationship between the application of the K3 management system with work motivation and work stress on nurses in the hospital. Method : The method used is a literature review or a comparison or analysis of one journal with other journals from various sources such as journal references, textbooks and e-books. Results : The results of this analysis state that it is important to carry out accreditation respondents. The positive impact of accreditation is increasing nurses' concern for patient safety indicators, namely improvements in problem reporting flow, compliance with standard operating procedures, communication between health officials, documentation, service facilities, health education, work environment and continuing education. Conclusion : a positive view of accreditation activities is a good start for hospitals to continue to improve quality of care. Because the main thing in service is the quality of service judged by clinical indicators of service, not completeness of documentation.
\end{abstract}

Keywords : Implementation, k3 management Work motivation, work stress, hospital. 


\section{Latar Belakang}

Salah satu upaya pemerintah untuk mendorong agar rumah sakit mengutamakan pelayanan, keselamatan dan perlindungan kepada masyarakat adalah dengan mewajibkan rumah sakit untuk melakukan akreditasi (Permenkes 012 th 2012). Menurut Permenkes 012 tahun 2012, akreditasi adalah pengakuan yang diberikan kepada rumah sakit karena telah berupaya meningkatkan mutu pelayanan secara berkesinambungan. Pengakuan ini diberikan oleh lembaga independen yang bertugas melakukan akreditasi dan sudah memperoleh pengakuan dari Menteri Kesehatan. Lembaga independen yang bertugas melakukan akreditasi terhadap rumah sakit di Indonesia adalah Komisi Akreditasi Rumah sakit (KARS). Menurut Lumenta (2003) akreditasi sangat berkaitan erat dengan mutu pelayanan yang diberikan rumah sakit. Artinya jika akreditasi dilakukan dengan baik, maka akan terjadi peningkatan mutu pelayanan rumah sakit. Namun menurut Pangestuti, Kuntjoro dan Utarini (2002) hasil akreditasi tidak otomatis meningkatkan kualitas pelayanan rumah sakit. Hal tersebut karena akreditasi pelayanan kesehatan di Indonesia belum menilai indikator klinis pelayanan kesehatan (Soepojo, Kuntjoro, dan Utarini, 2002). Pertanyaan mengenai dedikasi akreditasi terhadap mutu layanan pasien dan tingkat kesembuhan pasien juga dilontarkan beberapa ahli di luar negeri ( Hinchcliff, Greenfield, dan Moldovan, 2012).

Meskipun demikian, adanya kewajiban untuk melakukan akreditasi terhadap pelayanan yang diberikan mendorong hampir semua rumah sakit untuk melaksanakan program tersebut, apalagi pemerintah juga memberikan kewajiban kepada pemerintah pusat dan daerah untuk mendukung rumah sakit yang ada di daerahnya ketika melakukan akreditasi. Kementerian kesehatan menargetkan pada tahun 2014 seluruh rumah sakit di Indonesia sudah terakreditasi, minimal terakreditasi nasional, tetapi hingga tahun 2016 baru $284(11,3 \%)$ rumah sakit yang terakreditasi di Indonesia. ( Yankes, 2016).

Bagaimana pendapat perawat mengenai dampak akreditasi terhadap pelayanan keperawatan belum banyak diketahui. Oleh karena itu, penelitian ini akan mengungkap pendapat dan sudut pandang perawat mengenai dampak 
akreditasi terhadap pelayanan perawat yang diberikan kepada pasien.

\section{Tujuan}

Tujuan penulisan ini yaitu mengidenifikasi hubungan penerapan sistem manajemen $\mathrm{k} 3$ dengan motivasi kerja dan stres kerja pada perawat di rumah sakit.

\section{Metode}

Metode yang digunakan merupakan literatur review atau suatu perbandingan atau analisis antara satu jurnal dengan jurnal lainnya dari berbagai sumber seperti referensi jurnal, buku teks dan e-book.

\section{Hasil \& Pembahasan}

Temuan dalam penelitian ini menunjukkan bahwa perawat memiliki persepsi positif terhadap pelaksanaan akreditasi rumah sakit. Perawat berpendapat bahwa akreditasi mendorong perawat untuk lebih memperhatikan upaya keselamatan pasien di rumah sakit, diantaranya penerapan standar opeasional prosedur yang lebih baik dalam upaya pencegahan infeksi, mobilisasi pasien, dan asuhan keperawatan. Selain itu akreditasi juga mendorong perawat melakukan pendokumentasian secara lengkap, mendorong perawat melakukan pendidikan kesehatan kepada pasien dan keluarga secara intensif serta mendorong dokumentasi yang terintegrasi sehingga menimbulkan komunikasi antar tim kesehatan yang merawat pasien. Adanya komunikasi yang baik antar petugas medis ini sangat bermanfaat dalam pelayanan keperawatan, karena beberapa penelitian menunjukkan bahwa komunikasi perawat dengan dokter beum cukup baik dan akibat dari hal ini adalah pelayanan kepasien menjadi tidak optimal. Akibat persepsi bahwa akreditasi rumah sakit di Indonesia sangat bersih adalah adanya perbaikan fasilitas dan lingkungan rumah sakit.

Hal ini tercermin dalam hasl wawancara perawat yang menyatakan bahwa dengan akreditasi fasilitas menjadi lebih lengkap dan aturan kawasan bebas merokok di rumah sakit benar-benar diterapkan. Selain persepsi postif terhadap akreditasi, perawat di RSUD Setjonegoro dalam penelitian ini juga menganggap akreditai sebagai ujian yang harus dihadapi untuk mendapatkan sertifikat pengakuan. Pesepsi akreditasi sebagai ujian karena akreditasi rumah sakit di Indonesia masih bersifat menilai belum membina. Tim asesor akreditasi akan datang 3 hari 
untuk menilai dokumen, kemudian mendatangi petugas kesehatan yang sedang bertugas.

Adapun pembinaan terhadap rumah sakit diserahkan kepada Dinas Kesehatan Provinsi dalam hal ini Dinas Kesehatan Provinsi Jawa Tengah. Hal ini sangat berbeda dengan akreditasi yang dilakukan di Australia yang menggunakan akreditasi sebagai sarana pembinaan rumah sakit (Soepojo, Kuntjoro dan Utarini, 2002).

Perawat memiliki persepsi positif terhadap akreditasi, disamping itu perawat juga berharap agar semangat akreditasi ini tidak hanya selesai dengan selesainya penilaian. Persepsi positif ini sebaiknya dimanfaatkan sebaik-baiknya oleh pimpinan rumah sakit untuk memperbaiki pelayanan secara berkelanjutan.

Semngat ini dapat dijadikan modal untuk meningkatkan pelayanan dengan penilian kualitas indikator klinis pelayanan sehingga pasien akan benar benar merasakan perbedaan pelayanan yang diberikan rumah sakit.

\section{Kesimpulan \& Saran}

Penelitian ini menunjukkan bahwa perawat memiliki persepsi posiif terhadap pelaksanaan akreditasi di RSUD Setjonegoro Wonosobo. Dampak positif dari pelaksanaan akreditasi bagi pelayanan keperawatan adalah meningkatnya usaha keselamatan pasien yag dilakukan oleh perawat. Selain itu akreditasi juga memberikan dampak pada perbaikan fasilitas dan lingkungan kerja. Saran untuk penelitian selanjutnya adalah menilai dampak akreditasi terhadap mutu pelayanan klinis perawat.

\section{Daftar Pustaka}

Akhenizan A, Shaw C. (2012). The

Attitude of health care

professionals toward

accreditation: A systematic review of literature. J Family Community Med.; 19:74-80

Bawelle, (2013). Jurnal Hubungan Pengetahuan dan Sikap Perawat dengan Pelaksanaan Keselamatan Pasien (Patient Safety) di Ruang Rawat Inap RSUD Liun Kandage Tahuna. Program Studi Ilmu Keperawatan Fakultas Kedokteran Universitas Sam Ratulangi, ejournal keperawatan (e-Kp), Manado.

Dewi,Mursidah. (2012). Pengaruh Pelatihan Timbang Terima Pasien Terhadap Penerapan Keselamatan Pasien Oleh Perawat Pelaksana Di RSUD Raden Mattaher 
Jambi.Jurnal Health \& Suport.5,(3):647:652.

El-Jardali F, Jamal D, Dimassi H, Ammar $\quad \mathrm{W}, \quad$ dan Tchaghchaghian.(2008). The impact of hospital accreditation on quality of care: perception of Lebanese nurse. International Journal of quality of in health care. 20(5);363-371

Ho M, Chang H, Chiu Y, dan Norris J.L. (2014). Effects of hospital accreditation on Medical students:

A national qualitative study in Taiwan. Academic Medicine. Vol $89 ; 11$

Iskandar, Heru, Halimi Maksum, dan Nafisah. (2014). Faktor Penyebab Penurunan Pelaporan Insiden Keselamatan Pasien Rumah Sakit. Malang : Fakultas Kedokteran Universitas Brawijaya Malang, 2014 Nugroho, SriH.P., Sujianto,U. Supervisi Kepala Ruang Model Proctor Untuk Meningkatkan Pelaksanaan Keselamatan Pasien. Jurnal Keperawatan Indonesia.20, (1):56-64

Kementerian Kesehatan. Permenkes No 012 tahun 2012 tentang Akreditasi rumah sakit. 2012. Warta perundang-undangan

Manzo, B.F. (2012). Nursing in hospital accreditation process: practice and implication in the Works quotidian, Rev. Latin Am.emfermagem. Jan-Feb; 20(1)151:8 Notoatmodjo, S. (2003). Pendidikan dan Perilaku Kesehatan. Jakarta : PT. Rineka Cipta.

Poerwani S.K., dan Sopacua E. (2006). Akreditasi sebagai upaya peningkatan mutu pelayanan rumah sakit. Buletin Penelitian Sistem Kesehatan. 9(3); 125-133

Potter \& Perry, (2005). Buku Ajar Fundamental Keperawatan : Konsep, Proses, dan Praktik. Edisi 4. Jakarta : EGC.

Rahayu, Sri. (2011). Pengembangan Program Patient Safety Berdasarkan Awareness dan Komitmen Individu. RSUD Ibnu Sina Kabupaten Gresik

Rachmawati, Alifa Rizqia, dkk. (2017). ANALISIS PELAKSANAAN TUJUH LANGKAH MENUJU KESELAMATAN PASIEN DI RUMAH SAKIT ISLAM SULTAN AGUNG SEMARANG. JURNAL 
KESEHATAN MASYARAKAT (e-Journal) Volume 5, Nomor 1 (ISSN: 2356-3346)

R.H, Simamora. (2019). Buku Ajar Pelaksanaan Identifikasi Pasien. Uwais Inspirasi Indonesia

R.H, Simamora. (2019). Documentation Of Patient Identification Into The Electronic System To Improve The Quality Of Nursing Services. International Jurnal Of Sciensific \& Technology

R.H, Simamora. (2019). The Influence Of Training Handover Based SBAR Communication For Improving Patients Safety. Indian Journal Of Public Health Research \& Deveropment.

Soepojo P, Koentjoro T, dan Utarini A. Bechmarking system akreditasi rumah sakit di Indonesia dan Australia. 2002. Jurnal Manajemen pelayanan Kesehatan, 2.

Stolewinder J. (2004). A study of doctors' view on how hospital accreditation can assist them provide quality and safe care to consumers. Melbourne, Australia: Monash University, departemen of epidemiology and Preventive Medicine.
Widajat, Rochmanadji. (2009). Being a Great and Sustainable Hospital. Jakarta : PT Gramedia Pustaka Utama

Yusuf, Muhammad. (2017). Penerapan Patient Safety Di Ruang Rawat Inap Rumah Sakit Umum Daerah Dr.Zainoel Abidin.Jurnal Ilmu Keperawatan. 5,(1):85-88. 